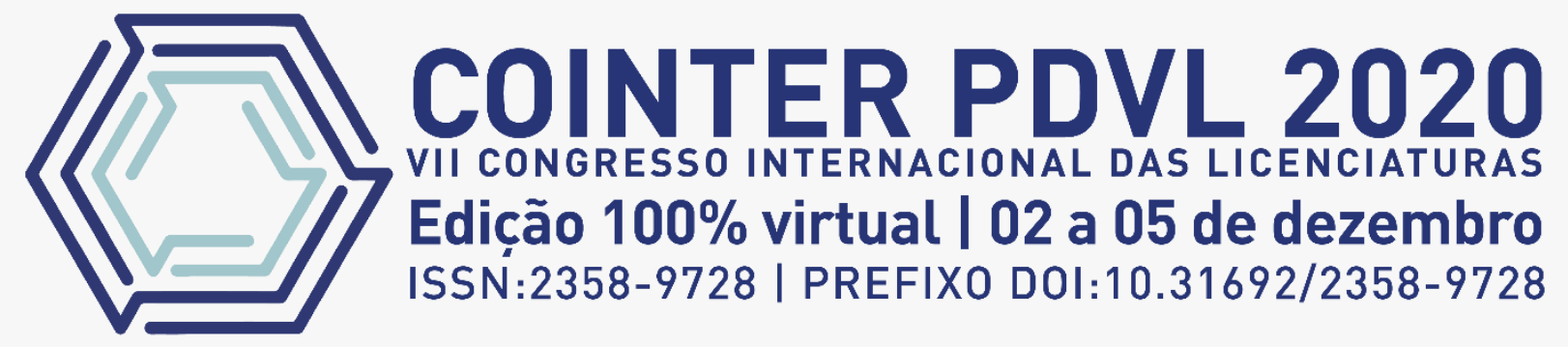

\title{
O OLHAR PARA PESQUISA NO VIÉS METODOLÓGICO DA PRODUÇÃO DE TRABALHOS CIENTÍFICOS NA LICENCIATURA EM QUÍMICA
}

\author{
EL MIRAR PARA LA INVESTIGACIÓN AL SESGO METODOLÓGICO DE LA \\ PRODUCIÓN DE TRABAJOS CIENTÍFICOS EN LA LICENCIATURA EN \\ QUÍMICA
}

\section{THE VIEW FOR RESEARCH IN THE METHODOLOGICAL ORIENTATION OF THE PRODUCTION OF SCIENTIFIC WORKS IN THE GRADUATION IN CHEMISTRY}

\author{
Apresentação: Comunicação Oral \\ Francisca das Chagas Alves da Silva ${ }^{1}$; Nyuara Araújo da Silva Mesquita ${ }^{2}$
}

DOI: https://doi.org/10.31692/2358-9728.VIICOINTERPDVL.0286

\begin{abstract}
RESUMO
Este estudo identificou elementos metodológicos do fazer científico ao analisar trabalhos de conclusão de curso (TCC) e resumos expandidos apresentados em eventos científicos da área de química. Estudo qualitativo e documental com análise de 11 resumos científicos e 10 trabalhos de conclusão de curso (TCC) feitos durante a formação inicial de dez alunos da licenciatura em química do Instituto Federal do Piauí para situar a iniciação no aporte metodológico da produção acadêmica destes licenciandos. As produções foram vinculadas à área de ensino de Química com temática diversificadas. Os trabalhos apresentaram fragilidades na construção do objeto, objetivo, referencial metodológico, delineamento da metodologia e discussão dos resultados com a literatura. A graduação é uma primeira aproximação dos alunos com a pesquisa e seus fundamentos que abre caminho para seu aperfeiçoamento em etapas posteriores da formação acadêmica. Educar pela pesquisa é um processo complexo e propõe formar um professor que trabalha a investigação como um princípio científico e educativo nas salas de aulas.
\end{abstract}

Palavras-Chave: pesquisa, química, professor.

\section{RESUMEN}

Este estudio identificó elementos metodológicos de la práctica científica mediante el análisis de trabajos de finalización de cursos (TCC) y resúmenes ampliados presentados en eventos científicos en el campo de la química. Estudio cualitativo y documental con análisis de 11 resúmenes científicos y 10 trabajos de conclusión de curso (TCC) realizados durante la formación inicial de diez estudiantes de pregrado en química en el Instituto Federal de Piauí para situar la iniciación en el aporte metodológico de la producción académica de estos pregrados. Las producciones estuvieron vinculadas al área docente de Química con temáticas diversificadas. Los trabajos presentaron debilidades en la construcción del objeto, objetivo, marco metodológico, diseño de la metodología y discusión de los resultados con la literatura. La graduación es un primer acercamiento de los estudiantes a la investigación y sus

\footnotetext{
${ }^{1}$ Doutoranda em Química PPGQ- IQ, Universidade Federal de Goiás, franciscasilva@ifpi.edu.br

${ }^{2}$ Professora de Química do PPGQ_IQ, Universidade Federal de Goiás, nyuara@ufg.br
} 
fundamentos, que abre el camino para su mejora en etapas posteriores de la formación académica. Educar a través de la investigación es un proceso complejo y propone formar un docente que trabaje con la investigación como principio científico y educativo en las aulas.

Palabras Clave: investigación, química, docente

\begin{abstract}
The training of researcher professor is important the educational research because it amplifies and improves studies realized in the scholastic scope. It is a challenge to insert the research in initial teacher training courses, since it implies to adapt the pedagogical policy project including fundamental elements of doing research. This study identified methodological elements of the scientific doing when analyzing works of conclusion of course (TCC) and extended abstracts presented in scientific events of the area. Qualitative, bibliographical and documentary study with analysis of 11 scientific abstracts and 10 TCC made during the initial training of ten graduates who defended in 2017.2. Productions linked to the area of Chemistry teaching with diverse subjects; the work presented weaknesses in the construction of the objective, methodological reference, methodology delineation and discussion of the results with the literature. Educating through research is not a simple process but proposes to train a teacher who works research as a scientific and educational principle in classrooms.
\end{abstract}

Keywords: research, chemistry, teacher

\title{
INTRODUÇÃO
}

A formação inicial docente abrange uma diversidade de conhecimentos gerais, específicos e os do âmbito pedagógico ambos devem ser contemplados para a formação do licenciando em Química. O documento que rege estas determinações, as Diretrizes Curriculares Nacionais para a formação docente (DCN) apresenta direcionamentos necessários para a formação do professor de Química com capacidade de entender os conteúdos químicos e abordá-los no contexto da educação básica (BRASIL, 2001). Além disso, as referidas diretrizes direcionam ações voltadas ao interesse no auto-aperfeiçoamento contínuo, curiosidade e capacidade para estudos extracurriculares individuais ou em grupo, espírito investigativo, criatividade e iniciativa na busca de soluções para questões individuais e coletivas relacionadas com o ensino de Química. O processo formativo tem que discutir as rápidas mudanças tecnológicas, interdisciplinaridade e ações que levem ao direcionamento para formar o professor no viés do pesquisador da sua prática.

A prática docente é uma atividade complexa que se desenvolve por meio do ensino em ambientes singulares, com situações imprevisíveis, carregadas de conflitos e que exige conhecimento para proposições de soluções (SCHON, 1992; MALDANER, 2006; ROSA, 2004). Portanto, desde a formação inicial docente em química o licenciando precisa ser direcionado para fazer pesquisa e perceber seu principal campo de investigação, a sala de aula e as questões relacionadas a educação química, instigando futuras contribuições para a melhoria 
da qualidade da educação.

Ainda sobre a pesquisa e seus documentos legais, a Resolução $N^{\circ} 07$ de abril de 2016 considera que a ética em pesquisa implica o respeito pela dignidade humana e a proteção devida aos participantes das pesquisas científicas envolvendo seres humanos (BRASIL,2016). Esta resolução ressalta que as Ciências Humanas e Sociais, nas quais vinculamos a educação e a área de Ensino de Química, têm especificidades nas suas concepções e práticas de pesquisa na medida em que nela prevalece uma acepção pluralista de ciência, bem como lida com atribuições de significado, práticas e representações, sem intervenção direta no corpo humano, com natureza e grau de risco. A área de Ensino de química está vinculada tanto a área de educação quanto à área de Ciências da Natureza.

Diante disso é constante a busca por alternativas curriculares e metodológicas, capazes de formar professores com os saberes docentes necessários para atuar de forma qualificada e enfrentar os desafios, fazendo pesquisa e se envolvendo com as questões da sala de aula. Isto mostra a necessidade da inserção do licenciando na escola desde o início do curso e o direcionamento para as competências necessárias para o fazer científico, ao pesquisar, mesmo que de forma inicial.

O espaço desta pesquisa foi o IFPI - Campus Picos, inaugurado em 28 de maio de 2007, como UNED (Unidade Educacional Descentralizada) do, então, CEFET-PI. Esta instituição é fruto da portaria $\mathrm{n}^{\circ} 1.291$, de 30 de dezembro de 2013, que estabeleceu o processo de expansão dos Institutos Federais (BRASIL, 2013).

O Campus Picos oferta, além da Educação Profissional Técnica na modalidade integrada e concomitante/subsequente, os cursos de Licenciaturas, Tecnólogo em ADS (Análise e Desenvolvimento de Sistemas) e Pós-Graduações lato sensu e cursos na modalidade Educação a Distancia (EaD). Neste campus há também diversos programas federais de educação, tais como, o PARFOR (Plano Nacional de Formação de Professores da Educação Básica), o Pronatec (Programa Nacional de Acesso ao ensino Técnico e Emprego) e Mulheres Mil, e programas de incentivo à docência e estímulo à pesquisa, tais como o PIBID e o PIBIC. A licenciatura em Química já tem onze anos e o Projeto Pedagógico do Curso (PPC) foi reformulado em 2015. O curso funciona no turno da noite com duração de quatro anos e meio, ou seja, nove semestres.

Os dez licenciandos que fizeram parte deste estudo por meio da análise dos seus trabalhos acadêmcios começaram a cursar química no ano de 2014 e concluíram em 2018 e entraram na instituição pelo processo seletivo do Exame Nacional do Ensino Médio (ENEM).

Neste sentido, o presente estudo buscou identificar e analisar elementos relacionados ao 
contexto metodológico do fazer científico no âmbito da formação de professores considerando a elaboração de trabalhos de conclusão de curso e publicações em eventos científicos produzidos ao longo da formação dos licenciandos do curso de Química do IFPI, Campus Picos.

\section{PRIMEIROS PASSOS DO PROFESSOR PESQUISADOR NO ENSINO DE QUÍMICA}

Na formação de professores de Química, é comum a prática e os saberes pedagógicos figurarem como aspectos de segunda categoria. Para superar esta valoração é preciso o amadurecimento das concepções que vigoram nos cursos de formação de professores (LEAL, 2010). Estes movimentos de mudanças estão em curso e decorrem de mobilização, vigilância e debates permanentes em busca de mudanças significativas tanto em torno da legislação quanto das ações promovidas nos espaços escolares.

No Brasil, os cursos de licenciatura foram criados em meados da década de 30 do século passado em função da preocupação com uma regulamentação para o preparo de docentes para escola secundária (ECHEVERRÍA; ZANON, 2010). Desde então os cursos sempre sofreram influência de diferentes leis e resoluções que alteraram suas estruturas curriculares.

O movimento de estudos sobre a formação inicial e continuada de professores em busca de modificações e melhorias, se potencializa nas décadas de 70 e 80, momento em que estava em discussão em âmbito nacional a reformulação das licenciaturas (PEREIRA, 2000). Estes movimentos foram essenciais para as mudanças promovidas na educação ao longo dos anos apesar do distanciamento que existe entre realidade e documentos legais.

Nos anos 60 e 70 as disciplinas científicas tinham a função de desenvolver o senso crítico tendo como princípio o método científico. Esta visão foi modificada pela lei 5.692/71 que implantou um ensino voltado para industrialização e modernização, ou seja, formando mão de obra especializada (KRASILCHIK, 2000).

O período de 1980 trouxe mudanças curriculares no ensino de Ciências, aspirando construir uma sociedade cientificamente alfabetizada (KRASILCHIK,1987; VEIGA,2002). Nesta década foi dada maior ênfase a questões sócio-políticas e ideológicas.

Nos anos 90 foram intensas as discussões sobre a formação de professores no Brasil gerando vários debates e contradições, inclusive no ensino de Ciências, e estas discussões já mencionavam a importância do professor pesquisador. Neste período a educação estava voltada para a formação de cidadão críticos, participativos e conscientes e os professores no exercício da docência buscavam sua identidade profissional ( NÓVOA, 1992). Era o início dos enfoques sobre a prática docente e os saberes pedagógicos.

Alguns destaques para a década de 1990 foram a promulgação da Lei de Diretrizes e 
Bases da Educação Nacional (LDB n 9394/96) e a elaboração dos Parâmetros Curriculares Nacionais (PCN) para o Ensino Fundamental e Médio. As críticas feitas por Schnetzler (1998) relaciona-se à formação inicial e a necessidade problematizar concepçõe simplistas sobre processos de formação docente, ensino e aprendizagem de química e as visões positivista da ciência. Por meio das novas regulamentações em nível nacional, o modelo $(3+1)$ vem sendo rediscutido buscando-se outros modelos mais adequados. Os cursos de licenciaturas eram estruturados para que tivessem três anos de conhecimento nas disciplinas de referências e depois um ano nas disciplinas pedagógicas (SOUZA, 2001).

Por muito tempo a prática docente alicerçou-se na transmissão de conhecimentos através de um sentido unilateral pautado na autoridade e saber do professor. Os discentes tinham as ações centradas na passividade, memorização e reprodução sem espaço para questionamentos, dúvidas ou construção de argumentos. Este modelo é denominado ensino tradicional vinculado muitas vezes ao positivismo e racionalidade técnica que vem sendo questionado e modificado ao longo dos anos (ECHEVERRÍA; ZANON,2010).

A formação de professores tem buscado promover mudanças metodológicas e curriculares para inserir o questionamento e a preocupação com a formação de educadores profissionais apesar dos vários empecilhos como a falta de estrutura das escolas, ausência de voz dos professores e as reformas educacionais pouco efetivas (MALDANER, 2013). Parte dessa inquietação passa pela formação de um professor que realiza pesquisa capaz de refletir sobre sua prática de forma crítica, de perceber a realidade da sala de aula para além do conhecimento na ação e de responder, reflexivamente, aos problemas do cotidiano das aulas (MALDANER, 2013). Este modelo alternativo denunciava a racionalidade instrumental e defendia a racionalidade prática.

$\mathrm{O}$ ato de pesquisar é inicialmente buscar resposta a uma questão inicial. Entretanto, o processo de busca e investigação requer a companhia de autores consolidados na área. A investigação dentro da área da Ciência exige um rigor técnico que perpassa pelo método e com isso envolve etapas fechadas que geralmente são conhecidos inicialmente no período da graduação. A pesquisa geralmente é apresentada ao aluno na educação superior, pois ao final do curso será necessário a construção de um trabalho de conclusão de curso (TCC), na forma de monografia ou artigo seguindo o rigor científico da área de estudo.

Para Moraes, Galiazzi e Ramos (2012) tudo começa com um questionamento para promoção de mudanças e novas atitudes por isso o perguntar é o movimento inicial da pesquisa inclusive na sala de aula. Demo (2000) corrobora com tal perspectiva ao afirmar que é fundamental assumir a dúvida expressa nos questionamentos como atitudes propedêuticas do 


\section{O OLHAR PARA PESQUISA NO VIÉS METODOLÓGICO}

processo de construção do conhecimento.

Moraes et al (2002, p.11) apontam três passos para o processo de pesquisa em sala de aula: questionamento, construção de argumentos e comunicação. Através do questionamento o aluno levanta hipóteses sobre uma problemática. Os argumentos irão confirmar ou refutar a problemática utilizando autores que já fizeram esta trajetória. A comunicação consiste na divulgação externa dos achados sobre a problemática inicial através de relatório ou ainda eventos científicos. Todo este processo transforma ações em conhecimento e promove a educação pela pesquisa.

Fazenda (2010) destaca alguns requisitos gerais para o pesquisar independente do referencial teórico ou a metodologia empregada, uma pesquisa implica o preenchimento de três requisitos:

- A existência de uma pergunta que se deseja responder;

- A elaboração (e sua descrição) de um conjunto de passos que permitam obter a informação necessária para responde-la;

- A indicação do grau de confiabilidade na resposta obtida

Estes pontos destacam o fazer cientifico delineado a partir de um problema seguido da elaboração de hipóteses e o recorte do referencial metodológico que corrobora com a questão pesquisada. Este processo é complexo principalmente para iniciantes. Por isso, a pesquisa precisa ser planejada antes do início das atividades, ou seja, feito por meio do projeto de pesquisa e orientado por um professor. É necessário haver um problema de pesquisa, um procedimento que gere informação relevante para a resposta e, finalmente, é importante demonstrar que esta informação decorre do procedimento empregado e que a resposta produzida não é apenas uma resposta possível, mas sim a melhor possível (FAZENDA, 2010).

Após esta etapa é construída a metodologia, conjunto de passos que possam gerar informações relevantes. Esta etapa não pode ser resumida a um simples procedimento de coleta de informações. Os estudantes devem aprofundar os estudos sobre os métodos, técnicas e procedimentos que compões o percurso metodológico. Obtidos os dados, o pesquisador terá diante de si um amontoado de respostas, que precisam ser ordenadas e categorizadas para que possam ser analisadas e interpretadas.

A fase mais complexa da pesquisa é a interpretação dos dados, isto é, expressar o verdadeiro significado do material, que se apresenta em termos do propósito do estudo (RUDIO, 1986; TRIVINÕS, 2015). O pesquisador deve ter maturidade para fazer ligações que a lógica lhe permite aconselhar; procederá comparações e, na base dos resultados alcançados, 
enunciará novos princípios e fará as generalizações apropriadas.

Para o professor pesquisar na área de Ensino de Química é necessário elencar arcabouços da área de humanas e também da área de química alinhando pontos para a construção de objetos de pesquisa voltados para a temas presentes nas salas de aula e na escola.

\section{METODOLOGIA}

Este estudo consiste em uma análise qualitativa e documental feita a partir da investigação de trabalhos científicos apresentados em eventos ao longo da formação inicial dos licenciandos em Química do IFPI, campus Picos, que defenderam o TCC no segundo semestre de 2018. O enfoque qualitativo está presente na área educação, pois responde muitas particularidades por meio de dados não mensuráveis (MINAYO,2002). O método qualitativo é usado tendo em vista descrever, compreender e explicar informações referentes a metodologias de ensino, concepções de conceitos, percepção de professores e alunos, entre outros.

A análise documental, é uma técnica de abordagem qualitativa que pode ser usada para investigar novas informações ou complementar as já conhecidas. (LUDKE; ANDRÉ, 2013). São considerados documentos deste estudo 13 TCC. Destes, três foram suprimidos porque apresentaram a autora do estudo como orientadora restando 11 trabalhos da área de Ensino de Química apresentados em eventos científicos ao longo dos 4 anos de formação inicial docente dos referidos licenciandos. A análise documental foi selecionada porque os documentos são fontes estáveis de informação; de baixo custo e acesso livre e o interesse do pesquisador foi estudar o problema a partir da expressão escrita dos sujeitos sobre elementos metodológicos do fazer pesquisa (LUDKE; ANDRÉ,2013).

As categorias de análises envolveram o fazer científico a partir da investigação da produção científica destes licenciandos baseando-se na RESOLUÇÃO $\mathrm{N}^{\circ}$ 019/2015/CONSELHO SUPERIOR do IFPI que rege os trabalhos de conclusão de curso das licenciaturas da instituição. O TCC tem como princípios: I - consolidação da instituição como um centro de produção científica, tecnológica, filosófica e artística voltado para a democratização do saber em prol da sociedade; II - integração entre o ensino, a pesquisa e a extensão nos termos do projeto político-pedagógico da instituição; III - produção de conhecimentos, soluções tecnológicas e informações voltadas para o desenvolvimento dos projetos acadêmicos e da pesquisa na Instituição; IV - desenvolvimento do espírito investigativo no discente. A partir do último item, consideramos a importância da pesquisa como balizadora do processo formativo e justificamos nosso foco investivativo.

As categorias de análise dos trabalhos investigados foram: 
1. Apronfundamento teórico a partir dos referenciais adotados

2. Percurso metodológico e os instrumentos de coleta de dados

As etapas do estudo consistiram em: (1) levantamento bibliográfico; (2) escolha e análise dos documentos; (3) interpretação dos dados e produção do trabalho científico.

\section{RESULTADOS E DISCUSSÃO}

\section{A PESQUISA POR TRÁS dOS TRABALHOS CIENTÍfICOS NA GRADUAÇÃO:} apronfundamento teórico a partir dos referenciais adotados

Uma análise sobre a pesquisa e os processos metodológicos mostrou que o currículo do curso de Química apresenta as disciplinas Metodologia Científica, Pesquisa em Ensino de Ciências e Química, TCC I e TCC II voltadas para a pesquisa científica. A seguir são descritos alguns elementos das disciplinas e ementas que reforçam a prática da pesquisa no curso de licenciatura em Química.

- Projeto Integrador IV: Análise e Discussão dos Eventos Científicos de Química Pura e de Ensino de Química.

- Pesquisa e Ensino de Ciências e Quimica: introdução a Pesquisa; Métodos quantitativos e qualitativos; Etapas do processo de pesquisa; Métodos de pesquisa nas grandes áreas da Química. A questão ética da pesquisa. Orientações sobre a elaboração de um Projeto de Pesquisa.

- Estágio Supervisionado IV: Observação e regência com visitas à indicações de seu objeto de estudo para elaboração de Trabalho de Conclusão de Curso (TCC).

- Trabalho de Conclusão de Curso I: Definição e delimitação da pesquisa. Redigir e qualificar um projeto de pesquisa científica atendendo aos padrões da metodologia científica e a normalização da ABNT, o manual de elaboração de monografia do IFPI, e as normas constantes no regulamento do núcleo de trabalho de conclusão de curso. Elaboração do projeto referente ao trabalho científico e/ou tecnológico, envolvendo temas abrangidos pelo curso.

Ao longo do curso, o licenciando ainda estuda Projeto Integrador até o quarto período e Estágio Supervisionado, na sequência até finalizar os componentes curriculares. Ao longo destas disciplinas o licenciando é instigado a conhecer os elementos metodológicos do fazer científico e a construir projetos de pesquisas voltadas para a área que poderão ser apresentados em eventos científicos.

Foram analisados 11 resumos expandidos apresentados em eventos locais, regionais e 
nacionais voltados para área de química e 10 TCC orientados por docentes do IFPI, campus Picos e defendidos por licenciandos que buscaram o grau acadêmico de Licenciados em Química.

A primeira fase do processo de elaboração de qualquer trabalho acadêmico é a determinação do assunto ou temática a ser tratada. Esta escolha sofre influência de fatores pessoais, sociais, psicológicos e metodológicos e critérios como: originalidade, importância, viabilidade e conhecimento do assunto (FIGUEIREDO; SOUZA,2011). As temáticas de estudo foram diversificadas e estão apresentadas na Figura 1.

Figura 1: Temáticas do Ensino de Química exploradas nos trabalhos científicos.

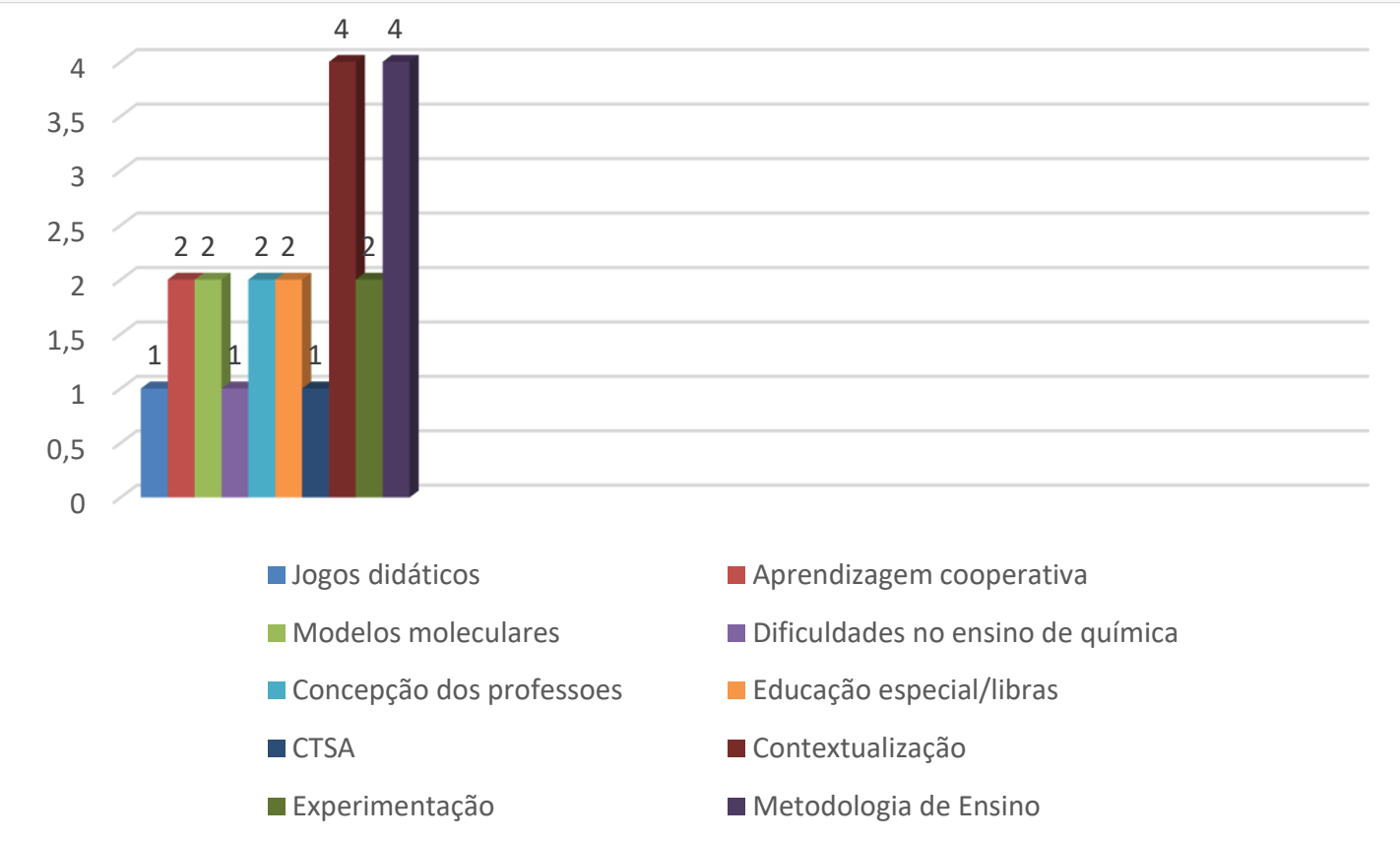

Fonte: a pesquisadora

Desde a graduação é importante o licenciando conhecer as áreas de pesquisa da Química, principalmente, do Ensino de Química e suas particularidades. No levantamento realizado, as temáticas mais exploradas foram: contextualização e metodologia de ensino.

Dos dez licenciandos que produziram os TCCs, sete já tinham feito trabalhos na forma de resumos para apresentar em eventos científicos. Esta produção inicial é importante, pois é construído um trabalho de menor dimensão, mas que contempla de forma sucinta todas as seções de um projeto científico percorrendo a fase de elaboração escrita até a apresentação.

Foram analisados os trabalhos com o intuito de investigar os primeiros passos do fazer científico de um grupo de licenciandos pois, a formação de um professor que faz pesquisa é um processo complexo. 


\section{O OLHAR PARA PESQUISA NO VIÉS METODOLÓGICO}

Os referenciais teóricos e metodológicos expressam muito sobre a temática do trabalho desde a formulação do problema; enunciado das hipóteses até a definição dos termos e hipóteses. Estabelecer as bases teóricas é um dos pontos mais relevantes no momento inicial da pesquisa, ou seja, porquê e de que modo o enunciado das hipóteses se relaciona aos teóricos consolidados na temática de estudo alinhado ao recorte do objeto de pesquisa feito pelo pesquisador.

Os trabalhos analisados exploraram referenciais teóricos da área da educação e do Ensino de Química com a especificidade da temática. A Tabela 1 mostra os resultados quanto ao levantamento feito para os dez TCC e onze resumos expandidos referente à delimitação da temática, problema, hipótese, objetivos e referencial metodológico.

Tabela 1: Análise do referencial teóricos dos TCC e resumos em eventos científicos

\begin{tabular}{l|c|c|c}
\hline $\begin{array}{c}\text { Trabalho de conclusão de curso } \\
\text { (TCC)/ resumo em eventos } \\
\text { científicos }\end{array}$ & Bem delimitado & $\begin{array}{c}\text { Superficialmente } \\
\text { Delimitado }\end{array}$ & Não delimitado \\
\hline 1. Apresentação do tema & 2 & 18 & 1 \\
\hline 2. Problema/Hipótese & 1 & 20 & - \\
\hline $\begin{array}{l}\text { 4. Utilização de } 2 \text { ou mais autores } \\
\text { para defesa dos conceitos } \\
\text { principais }\end{array}$ & 4 & 17 & - \\
\hline 5. Argumentação com os autores & 1 & 5 & 15 \\
\hline
\end{tabular}

Destaca-se falta de delimitação do problema, da hipótese e objetivos pouco claro da pesquisa, o que gera conflitos ao se buscar teóricos para um recorte da área de estudo. Quanto à utilização dos autores, todos os trabalhos citaram mais de dois (2) autores principais para construção do referencial metodológico sendo que dezoito (18) apresentaram recorte superficial da temática e três (3) realizaram uma abordagem alinhada com o tema do trabalho.

Em relação ao estudo dos autores consolidados na área, constatou-se pouca utilização de argumentações entre autores, no sentido de confrontar idéias, apenas quatro (4) trabalhos apresentaram este tipo de abordagem. Em alguns trabalhos identificou-se citações, tanto direta quanto indireta, em sequência sem argumentos intercalando às proposições apresentadas incluindo um TCC que apresentou como técnica de pesquisa a revisão da literatura. Para Fazenda (2010), um dos produtos da dificuldade de escrever é a chamada "colcha de retalhos" onde o pesquisador, por não possuir ainda um discurso próprio, utiliza-se ou apropria-se do discurso alheio, e, ao somar textos, não percebe que muitas vezes estes são desconexos ou até conflitantes.

Moreira (2011) destaca que tudo começa com o problema da pesquisa, hipóteses e objetivos, um processo, na qual a falta de um referencial é provavelmente a maior falha de 
muitos trabalhos em educação. Uma pesquisa feita sem referencial teórico é um estudo feito ao acaso e compromete resultados obtidos, isto é, estes não realimentarão a teoria.

Identificaram-se entre os TCC e os resumos expandidos que vinte (20) trabalhos utilizaram a sala de aula como espaço de pesquisa. A pesquisa em sala de aula é uma forma do professor e do aluno articularem-se em um processo de busca e construção do conhecimento, por meio do questionamento, da formulação de argumentos e da comunicação entre os indivíduos.

\section{Conforme Moraes, Galiazzi e Ramos:}

A pesquisa em sala de aula é uma maneira de envolver os sujeitos, alunos e professores, num processo de questionamento do discurso, das verdades implícitas e explícitas nas formações discursivas, propiciando a partir disso a construção de argumentos que levem a novas verdades (2012, p. 12).

O licenciando ainda como principiante no estudo de métodos e técnica de pesquisa é orientado com noções elementares, com a finalidade de produzir um bom projeto de pesquisa e ultrapassar com reflexão e experiência os desafios iniciais buscando maior profundidade nos trabalhos futuros. Contudo este é um processo complexo que vai melhorando com a experiência do pesquisador, logo requer muita prática e amadurecimento dos argumentos dissertativos e o envolvimento do licenciando no campo da pesquisa científica. A pesquisa em sala de aula, desde a formação inicial, propicia familiaridade e o conhecimento dos desafios e diversidade de possibilidades ao investigar este espaço.

\section{PERCURSO METODOLÓGICO E OS INSTRUMENTOS DE COLETA DE DADOS}

Desde a fase da elaboração de uma pesquisa é importante a estruturação da metodologia para possibilitar o cumprimento dos objetivos obtendo informações coerente com a realidade. No que se refere ao método de pesquisa dezessete (17) trabalhos apresentaram natureza qualitativas e buscaram investigar a participação em eventos científicos, as contribuições de gincanas, jogos, experimentos, compreensão de conceitos entre outros pontos voltados para o ensino de química; quatro (4) apresentaram o método qualitativo-quantitativo ao investigar por exemplo: avaliação de um jogo químico para smartfhone; análise de modelos moleculares; eficácia da experimentação em eletroquímica entre outros, não houve trabalhos com abordagem quantitativa.

A maioria dos licenciandos classificou seu método como qualitativo de forma coerente com os estudos da área de Ensino de Química. De acordo com Figueiredo e Souza (2011) os três tipo de classificação tem finalidades diferentes pois na medida que o objeto é traduzido e apresenta subjetividade, relativa a um fenômeno não mensurável, o método é o qualitativo. 


\section{O OLHAR PARA PESQUISA NO VIÉS METODOLÓGICO}

Ainda de acordo com Figueiredo e Souza (2011) se o método pretende enfocar o conhecimento de forma concreta, objetiva, mensurável e valendo-se de dados estatísticos, o método indicado é o quantitativo e quando o objeto admite a integração de ambos, o método é quali-quantitativo. Gatti (2002,p.29) faz uma ressalva para esta última classificação para a pesquisa em educação.

É preciso considerar que os conceitos de quantidade e qualidade não são totalmente dissociados, na medida em que de um lado a quantidade é uma interpretação, uma tradução, um significado que é atribuído à grandeza com que um fenômeno se manifesta (portanto é uma qualificação dessa natureza), e de outro ela precisa ser interpretada qualitativamente pois, sem relação a algum referencial não tem significado em si.

Os trabalhos sinalizam indícios de algum tipo de observação das instituições investigadas entretanto as metodologias não apresentam dados sobre qual o tipo de observação realizada sistemática, assistemática, participante e não-participante.

Em relação à técnica de pesquisa todos os trabalhos citaram a pesquisa bibliográfica inclusive um realizou revisão da literatura. Em relação ao tipo de pesquisa dezessete (17) fizeram uma pesquisa exploratória; quatro (4) não informaram. A pesquisa exploratória consiste em investigações empíricas, porém o objetivo é a formulação de questões ou de um problema, com tripla finalidade aumentar a familiaridade do pesquisador com o objeto, para realização de uma pesquisa futura (FIGUEIREDO; SOUZA, 2011).

De acordo com o tipo de informações que se deseja obter, há uma variedade de instrumentos que podem ser utilizados, e maneiras diferentes de operá-los. Quanto aos instrumentos de análise de dados percebeu-se que quatorze (14) trabalhos utilizaram questionários e dois (2) utilizaram entrevista semi-estruturada; um (1) utilizou questionário e entrevista; um (1) foi revisão bibliográfica e três (3) não identificaram os instrumentos utilizados.

O questionário consiste em perguntas ordenadas de forma clara e precisas sobre o objeto de estudo, problema e hipóteses redigido de maneira objetiva e subjetivamente. É um instrumento muito utilizado principalmente nas pesquisas quantitativas pois atinge um número de pessoas simultaneamente e obtém respostas rápidas e exatas. Atualmente utiliza-se a internet para enviar questionário só que o retorno do instrumento e muitas vezes comprometido, em média alcançam 25\% de devolução (MARCONI; LAKATOS, 2003).

Quanto à observação da formulação de questões para os instrumentos de coleta dos trabalhos analisados quatro (4) apresentaram questionários fechados em média com dez questões aplicadas para análise de conceitos prévios. O questionário aberto foi identificado em três (3) trabalhos com número de questões reduzidas para verificar a avaliação da atividade 
realizada. Foi identificado oito (8) trabalhos com questionário aberto e fechado geralmente aplicados um antes (pré-teste) e outro após a atividade (pós-teste) com o objetivo de identificar os conhecimentos prévios, opiniões, sugestões dos respondentes e para avaliar a atividade realizada.

Para identificar a relação da discussão dos resultados com a revisão de literatura nos trabalhos foi investigado a justificativa do questionário como instrumento de pesquisa. Apenas em quatro (4) trabalhos explicaram o porquê da escolha do questionário e complementaram com a literatura. Como a maioria dos trabalhos utilizou o questionário é importante destacar que a construção deste instrumento deve esta de acordo com os objetivos da pesquisa para a significativa validação dos dados ancorada pelos teóricos.

A entrevista semi-estruturada foi realizada em dois trabalhos que justificaram o porquê deste instrumento. Apenas um trabalho utilizou entrevista e um questionário aberto para identificar a opinião dos professores, esta estratégia é utilizada no método qualitativo para ampliar a qualidade dos dados (GIORDAN, VECCHI,1996).

De acordo com os estudos analisados por Greca (2002) diversos trabalhos não apresentam a discussão explicíta do percurso metodológico, fato identificado também nos trabalhos investigados, o que pode ser compreendido como fruto da inexperiência dos autores. Portanto, os trabalhos apresentaram fragilidades justificadas muitas vezes pela inexperiência dos autores ao planejar e construir trabalhos científicos e o trabalho de conclusão de curso. A formação do professor e a iniciação a pesquisa deve apresentar os elementos metodológicos do fazer científico desde a formação inicial buscando minimizar estes obstáculos e aumentar o número de trabalhos científicos voltados para investigação do ensino e os desafios para entender Química.

Moreira (2011) levanta alguns questionamentos que serve como sugestão para acadêmicos nos primeiros passos da construção do trabalho científico. Qual a teoria que fundamenta as hipóteses formuladas em relação ao problema? Como os resultados refletem na fundamentação teórica e qual a contribuição? Quais os conceitos chaves da pesquisa? Estes elementos metodológicos são essenciais para a construção do fazer científico no inicio da jornada do professor e pesquisador.

Obtidos os dados o pesquisador terá um conjunto de respostas, que precisam ser ordenadas organizadas para que possam ser analisadas e interpretadas nisso consiste a etapa de resultados e discussão. Este momento exige o amadurecimento do pesquisador porque os dados serão analisados em um processo de classificação feito por tabulação e codificação dos dados, ou seja, estabelecer categorias. Os trabalhos apresentaram seus resultados por meio de gráficos, 


\section{O OLHAR PARA PESQUISA NO VIÉS METODOLÓGICO}

tabelas, quadros e também de maneira descritiva. A maioria utilizou o questionário em alguns trabalhos foi identificado incoerências quanto ao objetivo e problemática do tema, consequentemente incompatibilidade nos resultados apresentados quanto a tabulação e decodificação dos dados. Os resultados apresentados em todos os trabalhos foram explorados de forma superficial; discutiram os autores e os resultados, porém ainda ficou lacunas em dezessete (17) trabalhos quanto a interrelação entre a discussão com os autores da área pesquisada e os argumentos com os achados da pesquisa. Apenas quatro (4) trabalhos apresentaram os dados e argumentaram tanto com os autores consolidados da área quanto com seus próprios achados da pesquisa.

\section{CONCLUSÕES}

Os trabalhos investigados se relacionam com à área de ensino de química e a maioria teve a escola e, principalmente, a sala de aula como espaço de investigação. Tal aspecto mostrase importante para a formação inicial do professor que busca realizar pesquisa. Diante dos trabalhos investigados foi identificada a iniciação a pesquisa na formação inicial do professor conforme descrito nas DCN e nos componentes curriculares do projeto pedagógico do curso. Os resultados analisados nos TCC e trabalho acadêmicos ainda denotam dificuldades elementares ao pesquisar quanto à delimitação do objeto pesquisado, o direcionamento metodológico e a discussão dos resultados, elementos basilares no processo de iniciação a pesquisa.

Estas dificuldades podem ser sanadas com maior envolvimento do licenciando em atividades de pesquisa e eventos científicos promovidos pela própria instituição direcionando os primeiros passos do fazer pesquisa que se refere a conhecer os autores consolidados na área e os principais trabalhos de pesquisa publicados. As instituições de ensino superior precisam ter o cuidado de implementar espaços nos quais as experiências de pesquisas possam ser partilhadas com a comunidade acadêmica amplamente e ter um olhar especial para a organização curricular dos cursos de formação de professores de química. A pesquisa precisa se constituir uma prática institucional democrática com questões da comunidade para promover melhorias e formar um professor que realiza pesquisa envolvido nas causas sociais que perpassam pelo Ensino de Química.

\section{REFERÊNCIAS}

BRASIL. Resolução $n^{\circ}$ 510, de 07 de abril de 2016. Dispõe sobre as normas aplicáveis a pesquisas em Ciências Humanas e Sociais. Diário Oficial [da] República Federativa do Brasil, 
Brasília, DF, 24 maio 2016. <Disponível em: http://bit.ly/2fmnKeD >. Acesso em: 10 out. 2020. » http://bit.ly/2fmnKeD

BRASIL. Parecer CNE/CES 1.303/2001 - Diretrizes Curriculares Nacionais para os Cursos de Química, Bacharelado e Licenciatura plena. Brasília: MEC, 2001. Disponível em: http://portal.mec.gov.br/cne/arquivos/pdf/CES1303.pdf

Brasil. Ministério da Educação. Portaria $n^{\circ} 1.291$, de 30/12/2013. Estabelece diretrizes para a organização dos Institutos Federais de Educação, Ciência e Tecnologia e define parâmetros e normas para a sua expansão". Brasília, DF. Publicado no D. O. U de 31/12/2013. Disponível em: http://portal.mec.gov.br/docman/41001-por-1291-2013-393-2016setec-pdf/file

BRASIL. Ministério de Educação e Cultura. LDB - Lei no 9394/96, de 20 de dezembro de 1996. Estabelece as diretrizes e bases da Educação Nacional. Brasília: MEC, 1996. Disponível em: http://portal.mec.gov.br/seed/arquivos/pdf/tvescola/leis/lein9394.pdf

CONSELHO SUPERIOR/INSTITUTO FEDERAL DE EDUCAÇÃO, CIÊNCIA E

TECNOLOGIA DO PIAUÍ (IFPI). Resolução $n^{\circ}$ 019/2015. Regulamenta o Trabalho

de Conclusão de Curso (TCC) nos cursos de licenciatura do IFPI. Teresina/PI: 2015. Disponível em:https://www.ifpi.edu.br/a-instituicao/pro-

reitorias/extensao/rei_proex_alteraregulamentonapne.pdf Acesso em: 10 set. 2020.

DEMO,P. Educar pela pesquisa.4.ed.Campinas: Autores Associados,2000.

ECHEVERRÍA,A.R.;ZANON,L.B. Formação superior em química no Brasil: práticas e fundamentos curriculares. Ijuí: Unijuí,2010.

FAZENDA, I. Metodologia da Pesquisa Educacional.12.ed.São Paulo: Cortez,2010.

FIGUEIREDO, A. M.; SOUZA, S. R. G. Como elaborar projetos,monografias, dissertações e teses: da redação científica à apresentação do texto final.4ed. Rio de Janeiro: Lumen Juris, 2011.

GALIAZZI, M. C.; MORAES, R.; RAMOS, M.G.; MALDANER, O. A. Educar pela pesquisa: as resistências sinalizando o processo de profissionalização de professores. Educar, Curitiba, $\mathrm{n}$. 21, p. 227-241. 2003.

GALIAZZI, M. C.; MORAES, R. Educação pela pesquisa como modo, tempo e espaço de qualificação da formação de professores de ciências. Ciência \& Educação, v. 8, n. 2, p. 237$252,2002$.

GATTI, B.A. A construção da pesquisa em educação no Brasil. Plano, 2002.

GIORDAN, A.;VECCHI,G. As origens do saber: das concepções dos aprendentes aos conceitos científicos.2ed.Porto Alegre: Artes Medicas,1996.

GRECA, I. M. Discutindo aspectos metodológicos da pesquisa em Ensino de Ciências: algumas questões para refletir. Revista Brasileira de Pesquisa em Educação em Ciência, São Paulo,v.2n.1,p.73-82,2002.

KRASILCHIK,M. O professor e o currículo das ciências. São Paulo: EPU/EDUSP,1987.

Reformas e realidade: o caso do ensino de Ciências. São Paulo em Perspectiva, v. 14, n. 1, p. 85-93, 2000.

LEAL, M.C. Didática da Química: Fundamentos e Práticas para o Ensino Médio. Belo Horizonte: Dimensão, 2010.

LUDKE, M.; ANDRÉ, M.E.D. A. Pesquisa em educação: abordagens qualitativas. São Paulo: $2^{\circ}$ ed.EPU,2013.

MALDANER, O. A. A formação inicial e continuada de professores de Química professor/pesquisador. Ijuí, RS: $4^{\circ}$ ed. Unijuí, 2013.

,et.al. A pesquisa sobre Educação em Ciências e formação de professores. In:

SANTOS,F.M.T; GRECA,I.M. (Org.). A pesquisa em ensino de Ciências no Brasil e suas metodologias. Ijuí: Ed. Unijuí, 2006.

MARCONI, M.A.; LAKATOS,E.M. Técnica de Pesquisa. São Paulo: 5ed.Atlas,2003. 
MINAYO, M. C. S. Entre vôos de águia e passos de elefante: caminhos da investigação na atualidade. IN: MINAYO, Maria Cecília de Souza; DESLANDES, Suely Ferreira (Orgs) Caminhos do Pensamento: Epistemologia e Método. Rio de Janeiro: Fiocruz, 2002.

MORAES, R.; GALIAZZI, M. C.; RAMOS, M. G. Pesquisa em sala de aula: fundamentos e pressupostos. In.: MORAES, Roque; LIMA, Valderez Marina do Rosário (org). Pesquisa em sala de aula: tendências para a educação em novos tempos. 3. ed. Porto Alegre: EDIPUCRS, 2012.

MORAES, R. Educar pela pesquisa: exercício de aprender a aprender. In: MORAES.R.;LIMA,V.M.R.(Orgs.). Pesquisa em sala de aula: tendências para a educação de novos tempos. Porto Alegre: EDIPUCRS,2002.

MOREIRA, M.A. Metodologia de Pesquisa em Ensino. São Paulo: livraria da Física, 2011.

NÓVOA, A. (org). Os professores e a sua formação. Lisboa: Dom Quixote, 1992.

PEREIRA, J. E. D. Formação de professores - pesquisas, representações e poder. Belo Horizonte: Antêtica, 2000.

ROSA, M. I. P. Investigações e ensino: articulações e possibilidades na formação de professores de ciências. Ijuí: Unijuí.2004.

RUDIO, F.V.Introdução ao projeto de pesquisa científica. Petrópolis, vozes, 1986.

SCHÖN, D. A. Formar professores como profissionais reflexivos. In: NÓVOA, António (org). Os professores e a sua formação. Lisboa: Dom Quixote, 1992.

SOUZA, P, N, P. LDB e educação superior: estrutura e funcionamento. 2.ed. São Paulo:

Pioneira Thomson Learning, 2001.

TRIVINÕS,A, N,S. Introdução à pesquisa em ciências sociais: a pesquisa qualitativa em educação. O positivismo; a fenomenologia; o marxismo, São Paulo; Atlas; 2015.

VEIGA, M. L. Formar professores para um conhecimento emancipatório pela via da educação em ciências. Revista Portuguesa de Formação de Professores.2, 49-62, 2002. 